\title{
Prevalence and Psychological Impact of Acne on Quality of Life among Undergraduate Medical students of Lahore, Pakistan
}

Ali Raza ${ }^{1}$, Ahmad Munib, ${ }^{1}$ Pashmal Yousaf, ${ }^{2}$ Ayesha Humayun, ${ }^{3}$ Ayesha Khalid, ${ }^{1}$ Ayeza Riaz, ${ }^{1}$ Maham Waseem, ${ }^{1}$ Fatima Asad, Fahad Zulfiqar, ${ }^{1}$ Awais Ahmad Cheema'

\begin{abstract}
Background: Acne Vulgaris is a rife and chronic dermal disorder, which commonly occurs in pubescent. This disease is characterized by the emergence of comedones, papules, pustules, nodules, or cysts which results from obstruction and inflammation of pilosebaceous units.

Objective: To finding out the prevalence and psychological impact of acne on the quality of life in undergraduate medical students of Lahore, Pakistan.

Methodology: A cross-sectional study was conducted during the month of October 2020, 291 among undergraduate medical students from eight medical colleges of Lahore, selected through simple random sampling, on both male and female undergraduate medical students. To assist them; they were given a simple grading criterion to self-diagnose their current acne severity and quality of life was evaluated by Cardiff Acne Disability Index. Data were analyzed by using SPSS version 22.

Results: A total of 213 (73.2\%) prevalence of acne was found among the participants who responded (291). No significant relation between acne severity and gender was found $(\mathrm{p}=0.151)$. There was no association between CADI score and gender $(\mathrm{p}=0.366)$. However, a significant correlation was found between CADI score and acne severity $(\mathrm{p}=0.000)$. In the population studied, $4.7 \%$ showed their acne severely impacting their quality of life, $27.7 \%$ have moderate, $58.7 \%$ have mild and $8.9 \%$ have no impact at all.

Conclusion: High Prevalence rate of acne and its significant negative impact on QOL indicates that it is a very common dermatological disorder. Effective interventions can make substantial contributions to derogate the impact of acne severity on QOL.
\end{abstract}

Keywords: Acne, Prevalence, Medical students, Quality of life

Article Citation: Raza A, Munib A, Yousaf P, Humayaun A, Khalid A, Riaz A, Waseem M, Asad F, Zulfiqar F, Cheema AA, . Prevalence and Psychological Impact of Acne on Quality of Life among Undergraduate Medical students of Lahore, Pakistan. JSZMC 2021;12(2):18-22

DOI: https://doi.org/10.47883/jszmc.v11i04.167

This Open Access Article in Journal of Sheikh Zayed Medical College is licensed under a Creative Commons Attribution- 4.0 International License(CC BY 4.0).

\section{Introduction}

Acne vulgaris is a common chronic dermatological disorder, predominant in adolescents. This disease is characterized by the emergence of comedones, papules, pustules, nodules, or cysts, which results from obstruction and inflammation of pilosebaceous units, mostly caused by Cutibacterium acnes. ${ }^{1,2}$ It is a global disease affecting $9.4 \%$ of the world population making it the eighth most common disease worldwide. ${ }^{3}$ There is a prevalence of around $5 \%$ in Pakistan. ${ }^{2}$ Acne is very common in adolescents and adults, due to the sudden surge of androgens at puberty in this age group. Sebaceous glands are hormonally responsive to these androgens thus increase blood hormones levels, results in increased secretions, and thus greater incidence in this age group. Acne profoundly affects healthrelated quality of life in a person. It may not only cause physical discomfort and disfigurement like facial scarring, but also can lead to psychological trauma, depression, dysphoria, social isolation, avoidance of daily activities, poor self-esteem, potential psychological disorders, and suicidal tendencies in extreme cases. ${ }^{4}$ Acne, despite not being a life-threatening or physically disabling illness, is still comparable to many chronic disabling illnesses like asthma, back pain, epilepsy, and psoriasis in its negative impact on quality of life. ${ }^{5}$ So, it is necessary to give attention to the negative impacts of acne on QOL while treating it. It has been found that acknowledging the psychological impact of acne and consideration of the quality of life in acne patients leads to better management of the disease. ${ }^{6,7}$ It is

1.Student,4th Year MBBS, Shaikh Khalifa Bin Zayed Al-Nahyan Medical and Dental College, Lahore.

2.Trainee Registrar, Department of General Surgery, Unit 1, Shaikh Zayed Postgraduate Institute, Shaikh Zayed Medical Complex, Lahore.

3. Head of Department, Department of Public Health and Community Medicine, Shaikh Khalifa Bin Zayed Al-Nahyan Medical and Dental College,

Shaikh Zayed Postgraduate Institute, Lahore.

Correspondence: Dr. Pashmal Yousaf, Trainee Registrar, Department of General Surgery, Unit 1, Shaikh Zayed Postgraduate Institute, Shaikh Zayed Medical Complex, Lahore. Pakistan. 
dismally stated that there is a lack of data regarding the prevalence and psychological impact of acne on its sufferers in Pakistan, and it has aspired that collection of aforementioned data on the disease may contribute to a better holistic approach, in the future. The objective current study was to find out the prevalence and psychological impact of acne on the quality of life in undergraduate medical students of Lahore, Pakistan.

\section{Methodology}

A questionnaire-based cross-sectional study was conducted in the month of October 2020 on undergraduate medical students studying in medical colleges of Lahore, Pakistan. Both male and female medical students were included in the study. Questionnaires with more than one item unanswered were excluded from our research analysis. To select sample size, the estimated population size ( $\mathrm{n}=15000$ approximately) was calculated by arithmetic sum of the number of students currently enrolled in all public and private medical colleges of Lahore, according to the number of seats allocated to each college by the Pakistan Medical Commission.

Through Epidata software, a sample size of $(n=283)$ was obtained with a $95 \%$ confidence level against an expected frequency of $75 \%$. Since the research was conducted in the middle of a pandemic. It was not possible to physically examine the participants, so the study was conducted online by sending a survey questionnaire to undergraduate medical students of eight medical colleges of Lahore, selected through simple random sampling. It was assumed that medical students have basic knowledge about acne since acne is a part of their curriculum. To further assist them; they were given a simple grading criterion to self-diagnose their current acne severity. The grading criteria are as follow: Clear: (there are no active acne lesions /only some dark/ red spots and redness present), Almost Clear: (there are few scattered whiteheads \& amp; blackheads \& amp; very few acne red bumps present), Mild: (Less than half of the face involved, Pimples with few black/whiteheads \& amp; acne bumps present), Moderate (More than half of the face is involved, many acne bumps and pimples present), Severe (Full face involved with many acne bumps \& amp; pustules), and Very
Severe (Full face along with other body parts is involved with pustules/cysts/nodules). Quality of life was evaluated by an authentic self-reported questionnaire CADI "Cardiff Acne Disability Index." CADI is a well-validated, self-reported questionnaire covering different domains of life with five questions and four answer groups. The five questions relate over the last month to feelings of agitation, anger, interference with social life, avoidance of public changing facilities, skin tone, and an indicator of current acne severity. Each question was scored as: a: (score 3), b: (score 2), c: (score 1), d: (score 0 ). The final score varies from 0 to 15. A higher score indicates more quality of life impairment. CADI scores were graded as no impact (0), mild (1-5), moderate (6-10), and severe Impact (11-15). Data were analyzed using the SPSS version 22 (Statistical Package for Social Studies) program.

\section{Results}

A total of 291 questionnaires were returned and all of them fulfilled our criteria of analysis so the response rate was $100 \%$. Out of 291 respondents, 213 (73.2\%) have experienced acne in the last five years so this shows that acne prevalence was high. The age range was between 17-26 years with a mean age of $21.5 \pm 2.87$ years. Among the respondents, 77 $(36.2 \%)$ were males, 134 (62.9\%) were females and $2(0.9 \%)$ preferred not to disclose their gender. In our report majority of students believed that they have experienced acne and rated its severity as clear $28.6 \%, 40.4 \%$ as almost clear, $21.6 \%$ as mild, $8.9 \%$ as moderate, $0.9 \%$ as severe (Table-I).

Relation between acne severity and gender calculated by the chi-square test shows no significant relation ( $p=0.151)$. Quality of life assessed by CADI questionnaire depicts a maximum score of 13 in both male and female respondents; the mean score was $4 \pm 3.09$. There was no association between CADI score and gender $(\mathrm{p}=0.366)$. However, a significant correlation was found between CADI score and acne severity $(p=0.000)$. CADI questionnaire responses are mentioned in a table-II. The psychosocial impact of acne on the participants was estimated by grading the final scores of the CADI, and $4.7 \%$ showed severe impact, $27.7 \%$ have moderate, $58.7 \%$ have mild and $8.9 \%$ have no impact on psychosocial functioning. 
Table-I: Distribution of Acne Severity Currently by Gender in Undergraduate Medical Students of Lahore, Pakistan

\begin{tabular}{|l|c|c|c|c|}
\hline \multirow{2}{*}{$\begin{array}{l}\text { Current Acne } \\
\text { Condition }\end{array}$} & \multicolumn{2}{|c|}{ Gender } & \multirow{2}{*}{ Total } \\
\cline { 2 - 5 } & Male & Female & $\begin{array}{c}\text { Preferred not } \\
\text { to Comment }\end{array}$ & \\
\hline $\begin{array}{l}\text { Clear (No active acne } \\
\text { lesions / Only some } \\
\text { dark/red spots and } \\
\text { redness) }\end{array}$ & 23 & 36 & 2 & \multirow{2}{*}{$61(28.6 \%)$} \\
\hline $\begin{array}{l}\text { Almost Clear (Few } \\
\text { scattered whiteheads } \\
\text { \& blackheads \& very } \\
\text { few acne red bumps) }\end{array}$ & 35 & 51 & 0 & \multirow{2}{*}{$86(40.4 \%)$} \\
\hline $\begin{array}{l}\text { Mild (Less than half } \\
\text { of the face involved, } \\
\text { Pimples with few } \\
\text { black/ whiteheads \& } \\
\text { acne } \\
\text { bumps) }\end{array}$ & 17 & 29 & 0 & $46(21.6 \%)$ \\
\hline $\begin{array}{l}\text { Moderate } \\
\text { (more than half of the } \\
\text { face is involved many } \\
\text { acne bumps and } \\
\text { pimples) }\end{array}$ & 2 & 17 & $213(100 \%)$ \\
\hline $\begin{array}{l}\text { Severe ( Full face } \\
\text { Involved with many } \\
\text { acne bumps and } \\
\text { pustules) }\end{array}$ & 0 & 1 & 0 & $19(8.9 \%)$ \\
\hline $\begin{array}{l}\text { Total } \\
\text { nyynn}\end{array}$ & $77(36 \%)$ & $134(62.9 \%)$ & $2(0.93 \%)$ & \\
\hline
\end{tabular}

Table-II: Specific responses of Cardiff Acne Disability Index (CADI).

\begin{tabular}{|c|c|c|}
\hline CAD I Questions & Response & No $(\%)$ \\
\hline \multirow{4}{*}{$\begin{array}{l}\text { Behavioral changes such as } \\
\text { being aggressive, frustrated, or } \\
\text { embarrassed during the last } \\
\text { month because of acne }\end{array}$} & Very much indeed & $17(8 \%)$ \\
\hline & A lot & $27(12.7 \%)$ \\
\hline & A little & $99(46.5 \%)$ \\
\hline & Not at all & $70(32.9 \%)$ \\
\hline \multirow{4}{*}{$\begin{array}{l}\text { Interference with daily social life, } \\
\text { social events, or relationships } \\
\text { with members of the opposite sex } \\
\text { due to acne over the last month }\end{array}$} & $\begin{array}{l}\text { Severely, affecting all } \\
\text { activities }\end{array}$ & $10(4.7 \%)$ \\
\hline & $\begin{array}{l}\text { Moderately, inmost } \\
\text { activities }\end{array}$ & $29(13.6 \%)$ \\
\hline & $\begin{array}{l}\text { Occasionally or in only } \\
\text { Some activities }\end{array}$ & $67(31.5 \%)$ \\
\hline & Not at all & $107(50.2 \%)$ \\
\hline \multirow{4}{*}{$\begin{array}{l}\text { Avoiding public changing } \\
\text { facilities or wearings swimming } \\
\text { costumes during the last month } \\
\text { because of acne }\end{array}$} & All of the time & $13(6.1 \%)$ \\
\hline & Most of the time & $15(7 \%)$ \\
\hline & Occasionally & $32(15.0 \%)$ \\
\hline & Not at all & $153(71.8 \%)$ \\
\hline \multirow{4}{*}{$\begin{array}{l}\text { Feelings regarding the } \\
\text { appearance of skin over the } \\
\text { last month }\end{array}$} & $\begin{array}{l}\text { Very depressed and } \\
\text { miserable }\end{array}$ & $9(4.2 \%)$ \\
\hline & Usually concerned & $63(29.6 \%)$ \\
\hline & Occasionally concerned & $108(50.7 \%)$ \\
\hline & Not bothered & $33(15.5 \%)$ \\
\hline \multirow{4}{*}{ Indication of current acne condition } & $\begin{array}{l}\text { The worst it could } \\
\text { Possibly be }\end{array}$ & $2(0.9 \%)$ \\
\hline & A major problem & $41(19.2 \%)$ \\
\hline & A minor problem & $115(54 \%)$ \\
\hline & Not a problem & $55(25.8 \%)$ \\
\hline
\end{tabular}

Figure-I: Grades of quality of life impairment and its impact on psychosocial functioning in acne cases of undergraduate medical students of Lahore, Pakistan.

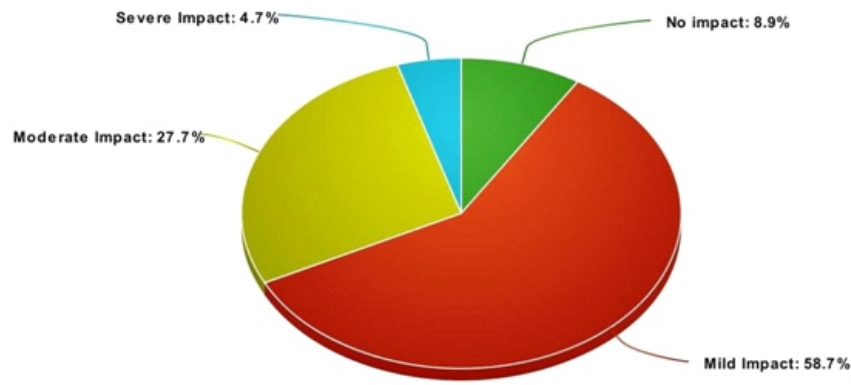

No impact $\square$ Mild Impact $\square$ Moderate Impact $\square$ Severe Impact

\section{Discussion}

Skin, a homeostatic and protective organ in its origin has evolved to provide a social function and is, now, subjectively used by humans to develop interpersonal relationships with the aid of its cosmetic appeal. Any disease process or deformity, which, hampers this social function/use may cause difficulty in developing and maintaining healthy relationships, which ultimately leads to the feeling of self-criticism, isolation, and social anxiety. Although the extent to which an individual faces this difficulty, is highly subjective, unique to every individual, and part of a spectrum with mere discomfort at one end of it, and suicidal tendencies at other extremes.

Thus, it is important that the impact of acne on quality of life should be studied and epidemiological data thus obtained must be applied clinically to ensure a better outcome for the patients. Many developed countries in the world, like the USA, ${ }^{7} \mathrm{UK}^{8}$ regularly conduct and report data on acne and its impact on QOL, and even developing countries like Iran ${ }^{9}$ conduct studies on the subject but sadly data from Pakistan is reported less commonly. In our study, which was conducted on the medical students in Lahore, the prevalence was found to be $73.2 \%$, which is similar to the value of $73 \%$ of another international research study ${ }^{10}$ in which participants had age group overlapping with this study and was also based on self-perception of acne. Similar, results were obtained in many studies. In our study, there were more females $(n=134)$ than males $(n=77)$. The possible reason could be that either female were predominantly affected, or they might generally be 
more interested in studies regarding acne. Also, the regional predominance of acne among females can be explained, due to many etiological factors like the use of cosmetics, Steroids, and OTC drugs to treat acne. Many international studies like by Conifer ${ }^{11}$ show that in the age group beyond 18 , acne was more common in females. Another research by Goulden ${ }^{12}$ confirmed this finding and claimed that in age beyond 20 years acne was relatively more common in females. Contrary to this, a study conducted on university going students in Syria ${ }^{13}$ shows that acne prevalence is higher among males. But many factors, like change in bathing and washing habits with seasonal variations, and the time at which research was conducted might have played a role in the research mentioned. ${ }^{13}$

In our study, there was no relationship between acne severity and gender, tested by the Chi-Square test. In several papers, acne severity was similar between the two sexes, but the quality of life was more impaired in women than in men. ${ }^{14,15}$ Contrary to these studies, some studies performed internationally found acne more severe in adult males. ${ }^{16,17}$ However in some studies, the incidence of more persistent acne was more common in females ${ }^{18}$ which might be explained by the most common pathological process underlying acne in this age group that is Hormonally responsive acne, which, from a hormonal point of view, puts certain females at disadvantage, due to some events, causing this hormonal flare (for example PCOS, ${ }^{19}$ menstrual cycle-related hormonal fluctuations, usage of OCPs) being gender-selective. However, such discussions are beyond the scope of this study.

A significant correlation was found between CADI score and acne severity $(p=0.000)$ in our study, with up to $4.7 \%$ of participants showing severe impact and $27.7 \%$ showing moderate impact, and $58.7 \%$ being mildly affected. The evaluation of acne severity in our study showed that "mild acne" is the most frequent form, and the least frequent form was "severe acne." Also, it was observed that CADI rises with the severity of acne. And as already established, the greater the CADI score, the poorer is the quality of life. In our study, the majority of the participants responded, having feelings of frustration and anger due to their acne condition. In another independent study, it was shown that having transference of anger, as a personality trait increases the risk of other comorbidities, for example, heart diseases. ${ }^{7}$ Overall $49.8 \%$ of the participants reported hindrance in their social life due to having acne. However, the majority of them $(71.8 \%)$ responded feeling no need to avoid wearing swimsuits or other costumes. This can be explained due to religious and cultural habits of wearing full clothes covering the whole body. Similar results were obtained, by another study, conducted by Nadia Shams on a comparable study group sharing the same culture and demographics. ${ }^{20}$ Up to $4.2 \%$ of participants described feeling very depressed and miserable and $29.6 \%$ of the participants were 'usually concerned' about their skin appearance.

While grading their current acne condition $19.2 \%$ of participants reported it as a major problem and 54\% reported feeling it as a minor problem. Whereas $0.9 \%$ reported it as worst as it could be. Many studies have shown that incidence of antidepressants usage, mood disturbances, and even suicidal ideation increases due to acne. ${ }^{4,21,22}$ Addressing patient feelings about their skin is important and even leads to better treatment adherence which ultimately improves their quality of life. ${ }^{23}$ It would be worthwhile to consider the limitations of this study before deducing a result. Firstly, since it was a questionnaire-based study and the severity of acne was scaled personally by the participants it might have led to subjective bias, and online setting although succeeded in providing comfort and privacy to the participants, unfortunately, provided no opportunity to subject them to rigorous and unbiased examination. Secondly, there was a lack of regional data, reported on the subject matter, and thus no reference point to compare with/overlap results found in our study.

\section{Conclusion}

In our study acne prevalence rate was found to be high, and there was a significant negative impact of acne on quality of life. Further studies are needed to be conducted in the region to get a more meaningful conclusion. Nonetheless, clinicians while attempting to treat acne must look for the signs of psychosocial, and other morbidities in their patients and may take appropriate interventions if needed. A better doctorpatient relationship, with proper history, must be promoted to address any fear or concerns patients might have about their condition. 
Authors Contribution: ABS: Conception of work and Drafting. AA: Conception of work Interpretation of data and revising. RM: design of work and revising. JI: Analysis of data and drafting.

All authors critically revised and approve its final version.

Conflict of Interest: Authors has declared no conflict of interest.

Sources of Funding: The source of funding was self.

\section{Disclaimer: None}

\section{References}

1. Keri JE. Acne Vulgaris, Dermatological Disorders. MSD Manual. 2020.

2. Baba O, Mobeen A. Prevalence and Psychological Impactr of Acne Vulgaris in Female Undergraduate Medical Students of Rawalpindi and Islamabad, Pakistan. Cureus 2019;11(9):e5722-e.

3. Tan JK, Bhate K. A global perspective on the epidemiology of acne. The British Jour of Derma 2015;172 Suppl 1:3-12

4. Hazarika N, Archana M. The Psychosocial Impact of Acne Vulgaris. Indian J Dermatol2016;61(5):515-20.

5. Cresce ND, Davis SA, Huang WW, Feldman SR. The quality of life impact of acne and rosacea compared to other major medical conditions. Journal of Drugs in Dermatol 2014;13(6):692-7.

6. Fakour Y, Noor MP, Ameri H, Ehsani AH, Mokhtari L, Khosrovanmehr N. The effect of isotretinoin (roaccutane) therapy on depression and quality of life of patients with severe acne. Iran J Psychiatry. 2014;9(4):237-40.

7. Rapp DA, Brenes GA, Feldman SR, Fleischer AB, Jr., Graham GF, Dailey M, et al. Anger, and acne: implications for quality of life, patient satisfaction, and clinical care. The British Jour of Dermatol 2004;151(1):183-9.

8. Walker N, Lewis-Jones MS. Quality of life and acne in Scottish adolescent schoolchildren: use of the Children, Dermatology Life Quality Index (CDLQI) and the Cardiff Acne Disability Index (CADI). J European Academy of Derma and Venereol 2006;20(1):45-50.

9. Aghaei S, Mazharinia N, Jafari P, Abbasfard Z. The Persian version of the Cardiff Acne Disability Index. Reliability and validity study. Saudi Medical Jour 2006;27(1):80-2.

10. Collier CN, Harper JC, Cafardi JA, Cantrell WC, Wang W, Foster KW, et al. The prevalence of acne in adults 20 years and older. Jour American Academy Dermatol 2008;58(1):56-9.
11. Cunliffe WJ, Gould DJ. Prevalence of facial acne vulgaris in late adolescence and in adults. British Medical Jour 1979;1(6171):1109-10.

12. Goulden V, Stables GI, Cunliffe WJ. Prevalence of facial acne in adults. J American Academy Dermatology. 1999;41(4):577-80.

13. Al-Kubaisy W, Abdullah NN, Kahn SM, Zia M. Sociodemographic Characteristics of Acne among University Students in Damascus, Syria. Epidemiology Research International 2014;2014:974019.

14. Berg M, Lindberg M. Possible gender differences in the quality of life and choice of therapy in acne. Jour European Academy Dermatology and Venereol 2011;25(8):969-72.

15. Yahya H. Acne vulgaris in Nigerian adolescents prevalence, severity, beliefs, perceptions, and practices. Dermatology Unit, Department of Medicine, Barau Dikko Specialist Hospital, Kaduna, Nigeria.

16. Skroza N, Tolino E, Mambrin A, Zuber S, Balduzzi V, Marchesiello A, et al. Adult Acne Versus Adolescent Acne: A Retrospective Study of 1,167 Patients. J Clin Aesthet Dermatol 2018;11(1):21-5.

17. Tan JK, Li Y, Fung K, Gupta AK, Thomas DR, Sapra S, et al. Divergence of demographic factors associated with clinical severity compared with the quality of life impact in acne. Jour Cutan Med and Surg 2008;12(5):235-42.

18. Williams C, Layton AM. Persistent acne in women: implications for the patient and therapy. American Jour Clinic Dermatol 2006;7(5):281-90.

19. Franik G, Bizoń A, Włoch S, Kowalczyk K, BiernackaBartnik A, Madej P. Hormonal and metabolic aspects of acne vulgaris in women with polycystic ovary syndrome. European Review for Medical and Pharma Sciences. 2018;22(14):4411-8.

20. Nadia Shams FN, Sumayya Zeeshan, Sadaf Ahmed, Shazia Farhat,, Seetlani NK. Cardiff Acne Disability Index-Based Quality Of Life In Acne Patients, Risk Factors And Associations. Jour LUMHS 2018;17(01):29-35.

21. Marqueling AL, Zane LT. Depression and suicidal behavior in acne patients treated with isotretinoin: a systematic review. Seminars in Cutan Med Surg 2005;24(2):92-102

22. Purvis D, Robinson E, Merry S, Watson P. Acne, anxiety, depression and suicide in teenagers: a cross-sectional survey of New Zealand secondary school students. Jour Pediatrics and Child Health 2006;42(12):793-6.

23. Renzi C, Picardi A, Abeni D, Agostini E, Baliva G, Pasquini $\mathrm{P}$, et al. Association of dissatisfaction with care and psychiatric morbidity with poor treatment compliance. Archives of Dermatol 2002;138(3):337-42. 